\section{Half and half in the national parks}

\section{Brian Bertram}

A Field Guide to the National Parks of East Africa. By John G. Williams and Norman Arlott. Pp.336. ISBN 0-00-219215-2. (Collins/Stephen Greene Press: 1982.) £7.95, \$29.95.

LIKE ALL Gaul, this handy field guide is divided into three parts. The first part surveys the national parks, game reserves and other faunal areas of Kenya, Tanzania and Uganda, the second is a guide to the larger mammals and the third a guide to the commoner birds of East Africa.

Unlike all Gaul, the standard of the three parts varies widely. The 70 pages on the mammals are well-presented and accurate; they are in effect the same as in the original 1967 version of this field guide. With the help of 13 pages of illustrations, they enable the visitor to identify almost any mammal he is likely to encounter. The 92 pages on the commoner birds are also good, and are the completely new part of the book. They replace the section in the previous edition which dealt with the rarer birds, and instead provide a condensed version of its companion volume on the birds one is more likely to see. Fifteen pages of effective colour illustrations help in the identification.

But as for the remaining part, "Oh dear" was my reaction. The opening 160 pages on the national parks and other wildlife areas are absolutely riddled with mistakes, and are going to mislead a great many people. Partly this is because they are hopelessly out of date, and have not been changed from the previous edition. Thus, to pick out just a couple of examples, the area of Meru National Park is now less than half the area John Williams states, and the "motor boat available for anyone wishing to explore the country from the rivers" was actually burnt to ashes at least a dozen years ago.

Other errors abound on the maps, caused partly by some careless re-drawing of long out-of-date maps. Thus roads (in Tsavo) and boundaries (in Amboseli) are often in the wrong place, and lodges are omitted (in Serengeti) or misplaced (in Tsavo). Even whole reserves are misplaced - one is shown over $200 \mathrm{~km}$ away from where it actually is. Advice on routes is often wrong and details in the species lists for the parks are faulty; for example the abundant hippo is omitted from Tsavo (despite a successful film about them there), and Patas monkeys have not been seen in Meru by anyone who has worked there for long. And so on.

This is very sad, because there is a wealth of knowledgeable people in East Africa who could have weeded out almost all of these mistakes, and made the book far more useful. As it is, one has to say "Don't trust the first half of it". But there is no other comparable guide, so if you are going to East Africa you had better get hold of it, warts and all. And take with it a pinch of salt and some proper maps.

Brian Bertram is Curator of Mammals at The Zoological Society of London.

\section{Private lives}

\section{John R. Krebs}

The Discovery of Animal Behaviour. By John Sparks. Pp.288. ISBN 0-00-219061-3. (Collins/Little, Brown: 1982.) £12.95, $\$ 24.95$.

FOLLOWING along the now well-used trail opened up by Life on Earth, The Discovery of Animal Behaviour is the book of the television series recently shown on $\mathrm{BBC} 2$. The text follows almost verbatim the script of the programmes, and although well written it loses some of its impact when not accompanied by the film. But pictures there are in plenty; every second page is a double-sided colour plate of high quality.
For those unfamiliar with the series, the book is essentially a history of ethology, highlighting the contributions and circumstances of key figures from the middle ages to the 1960s. The "stars" include Ray, White, Leroy, Darwin, Romanes, Spalding, Loeb, Watson, Skinner, Pavlov, Lorenz, Tinbergen and von Frisch, a fairly uncontroversial list. In spite of its title, the last two chapters of the book (covering the mid-twentieth century) are almost exclusively about ethology and sociobiology: psychologists fade out after Skinner and Harlow.

Those hoping to gasp at arcane marvels of animal behaviour or to be enlightened about the big issues in present-day ethological research may be disappointed, for this is as much an account of the people as of their subject. It is hardly gripping stuff, especially for those not familiar with animal behaviour; after all, most naturalists are men of quotidian habits.

One of the nice features of the book is the way in which the discoveries and attitudes of individuals are related to their personal circumstances. For many the stimulus and opportunity to study animal behaviour was linked with relaxing country residences - a mill by an Austrian lake, a rambling house close to the Danube, a country cottage at Dunskaith; in stark contrast, we are told that the theoretician W.D. Hamilton did much of his thinking while waiting at Waterloo Station!

Another recurrent theme is how easily scientists were led to generalize their findings to an unreasonable point. Loeb, the discoverer of phototaxis considered whether the human mind could be explained in terms of taxes and tropisms; Romanes asked whether spiders might appreciate music; and Schelderup-Ebbe, the man who discovered dominance hierarchies, subsumed the relationship between God and the Devil in his account of social organization. It is easy to smile, but less easy to see whether or not one has one's own musical spiders.

John $R$. Krebs is Lecturer in Zoology at the Edward Grey Institute and E.P. Abraham Fellow of Pembroke College, University of Oxford.

\section{IMAGE \\ UNAVAILABLE \\ FOR \\ COPYRIGHT \\ REASONS}

Home on the range - wildebeest (gnu) in the Amboscli National Park, Kenya. The snow-capped Kilimanjaro rises in the background. (Photograph David Keith Jones.) 